\title{
AVIAN HERBIVORY: AN EXPERIMENT, A FIELD TEST, AND AN ALLOMETRIC COMPARISON WITH MAMMALS
}

\author{
Jan A. van Gils, ${ }^{1}$ Abel Gyimesi, and Bart van Lith \\ Department of Plant-Animal Interactions, Centre for Limnology, Netherlands Institute of Ecology (NIOO-KNAW), \\ Rijksstraatweg 6, 3631 AC Nieuwersluis, The Netherlands
}

\begin{abstract}
Mechanistic studies on herbivore functional responses have largely taken place in mammals; very little has been done in herbivorous birds so far. Here we aim to fill that gap by experimentally quantifying the (short-term) functional response of a large avian herbivore, the Bewick's Swan (Cygnus columbianus bewickii). We explicitly distinguish between encounter-limited and handling-limited foraging by analyzing the results in the framework of the models of D. E. Spalinger and N. T. Hobbs, originally developed for mammalian herbivory. Bite size in captive swans was experimentally manipulated by varying sward height. The time interval between two bites increased with bite size, which supports the handlinglimited model (process 3) and rejects the encounter-limited models (processes 1 and 2). Subsequently, we took the obtained functional response parameters into the field in order to predict, from measurements of sward height, (1) bite sizes, (2) handling times, and (3) shortterm intake rates in free-ranging swans. Indeed, for all three variables, the observed values closely matched the experimentally based predictions. Finally, we review functional response parameters available in the literature on avian herbivores and scale them allometrically in relation to mammals. This analysis revealed that maximum bite sizes, and therefore maximum intake rates, in herbivorous birds are smaller than in herbivorous mammals. We hypothesize and provide evidence that birds compensate by longer daily foraging times.
\end{abstract}

Key words: allometry; Bewick's Swan; bite size; chewing; cropping; Cygnus columbianus bewickii; foraging; functional response; grazing; handling time; herbivory; intake rate.

\section{INTRODUCTION}

The relation between a forager's intake rate and its food supply (i.e., the functional response) plays a central role in population ecology (e.g., Vandermeer and Goldberg 2003). Therefore, a basic understanding of factors controlling a forager's intake rate seems critical for progress in this field of science. Over the past decades, Holling's disk equation (Holling 1959) has been most influential in this respect (Jeschke et al. 2002). In this short-term functional response model (i.e., dealing explicitly with the constraints acting while foraging; Bergman et al. 2001), a forager alternates between searching for food and handling food (two mutually exclusive activities), yielding a Type II functional response (Holling 1966) in which intake rate increases asymptotically with food abundance. In spite of such

Manuscript received 31 May 2006; revised 8 February 2007; accepted 20 February 2007. Corresponding Editor: B. P. Kotler.

${ }^{1}$ Present addresses: Department of Plant-Animal Interactions, Centre for Limnology, Netherlands Institute of Ecology (NIOO-KNAW), Rijksstraatweg 6, 3631 AC Nieuwersluis, The Netherlands; School of Biological Sciences, University of Bristol, Woodland Road, Bristol BS8 1UG UK; Royal Netherlands Institute for Sea Research (NIOZ), PO Box 59, 1790 AB Den Burg, The Netherlands.

E-mail: j.vangils@nioo.knaw.nl simplified assumptions that seem to be specific for true predators feeding on discrete prey items, the model not only fits intake rates of predators (e.g., Piersma et al. 1995), but often fits short-term intake rates of herbivorous consumers as well (e.g., Augustine et al. 1998, Nolet et al. 2001). However, as pointed out and explored by Spalinger and Hobbs (1992), several alternative mechanisms, other than the trade-off between searching and handling, could account for Type II functional responses seen so often in herbivores.

Central in the herbivore models developed by Spalinger and Hobbs (1992) is the decomposition of handling time into two sequential stages that are typical for herbivorous foraging: cropping (i.e., the act biting off plant tissue) and chewing (i.e., the act of processing the bite in the mouth until swallowing it). These authors further assume that (1) cropping and chewing are mutually exclusive (a mouth can only perform one function at any given time; but see Ginnett and Demment 1995), (2) cropping slows down searching (but does not exclude it), and (3) chewing and searching are entirely non-mutually exclusive. Based on spatial and morphological characteristics of plants, these assumptions enabled Spalinger and Hobbs to distinguish three possible mechanisms applying to herbivore foraging. In process 1 , herbivores feed on spatially dispersed, hidden plants and are therefore either searching or 


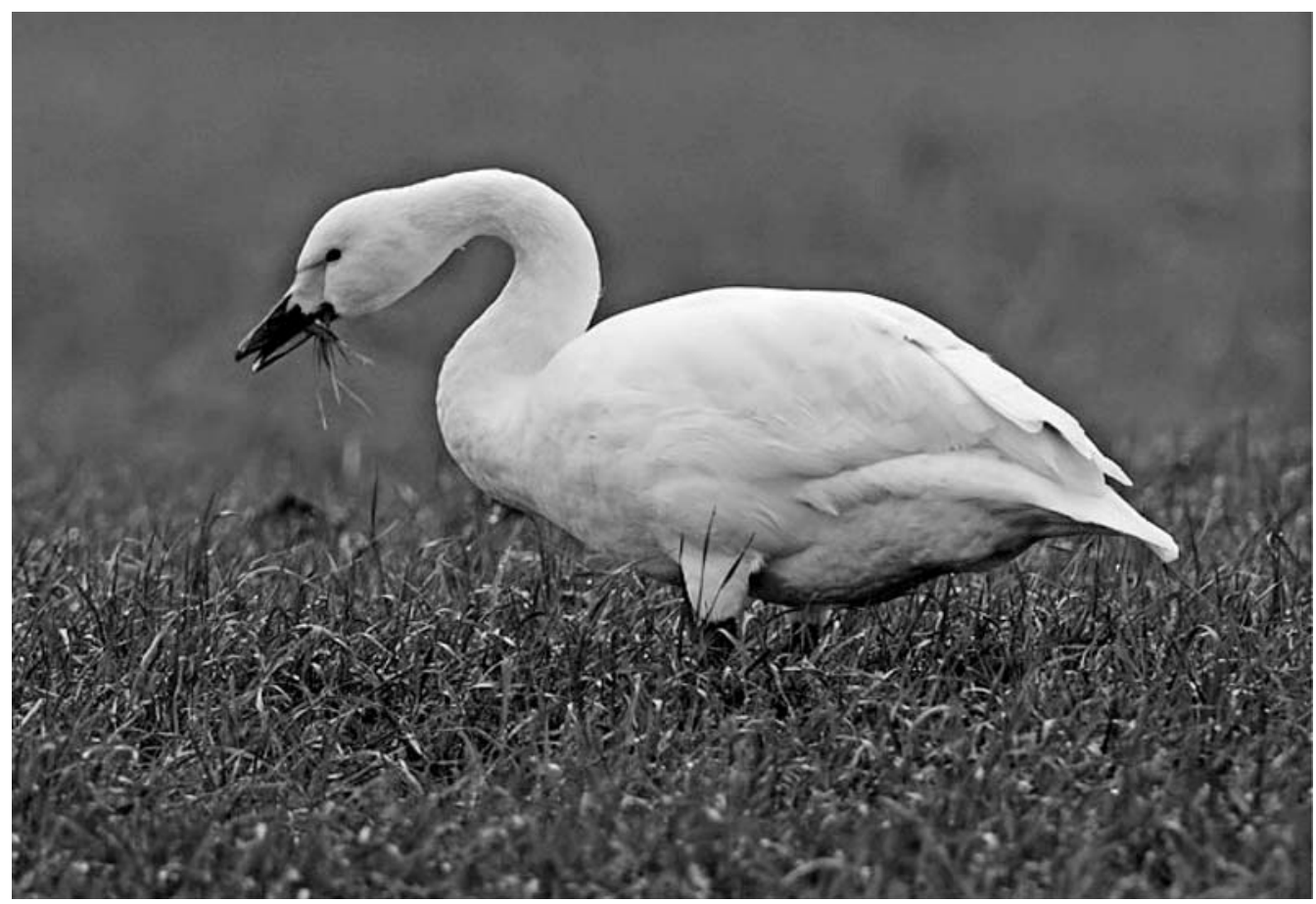

Fig. 1. A free-ranging Bewick's Swan taking a large bite of grass. The study was conducted in Heteren, The Netherlands. Photo credit: Paul Cools.

handling or doing both at the same time (due to this latter activity this process differs from Holling's disk equation). In process 2 , herbivores feed on spatially dispersed, apparent plants and are therefore either moving toward a new bite or handling or doing both at the same time. In process 3 , herbivores feed on spatially concentrated, apparent plants and are therefore always handling their bites.

Up to now, the models developed by Spalinger and Hobbs have mainly been tested and verified in mammalian herbivores, for which they were originally developed (e.g., Gross et al. 1993, Bradbury et al. 1996, Illius et al. 2002, Hobbs et al. 2003, Searle et al. 2005). However, as shown by Hewitt and Kirkpatrick (1996) and Durant et al. (2003), the models seem to apply to avian herbivory under experimental conditions as well. Whether they apply to free-ranging avian herbivores remains as yet untested, but seems highly probable. For example, freeranging Brent Geese (Branta bernicla) feeding on respectively Zostera and Plantago showed Type II functional responses (Charman 1979, Prop 1991), which is highly suggestive. By mechanistically unraveling such responses, models on population dynamics of avian herbivores and their food resources, which in the past were often based on phenomenological asymptotic functional responses (Lang et al. 1998, Pettifor et al. 2000), could produce more realistic predictions. In addition, deviations from a Type II response, such as the "dome-shaped" functional response recently report- ed in a range of relatively small avian herbivores (Van der Wal et al. 1998, Therkildsen and Madsen 2000, Lang and Black 2001, Bos et al. 2004), may be better understood in the light of the proposed competition between cropping and chewing on the one hand and between cropping and searching on the other.

In this paper, we focus on short-term or so-called instantaneous intake rates by explicitly distinguishing between the encounter-limited (process 1 and 2) and the handling-limited (process 3) Spalinger and Hobbs models in a large grass-eating avian herbivore, the Bewick's Swan (Cygnus columbianus bewickii; see Fig. 1 and Plate 1). We do so by experimentally manipulating bite size in captive swans (through varying sward height). Subsequently, we take the obtained functional response parameters into the field to see whether we can predict short-term intake rates in free-ranging swans from measurements of naturally available sward heights. Finally, we review functional response parameters available in the literature on avian herbivores and scale them allometrically in relation to mammals.

\section{Distinguishing Encounter-Limited Foraging FROM HANDLING-Limited Foraging}

Because in the Spalinger-Hobbs models searching time $\left(T_{\mathrm{s}}\right)$ and handling time $\left(T_{\mathrm{h}}\right)$ can completely overlap (in contrast to the disk equation), foraging time $T_{\mathrm{f}}$ between two bites is simply determined by whichever activity takes longest: 


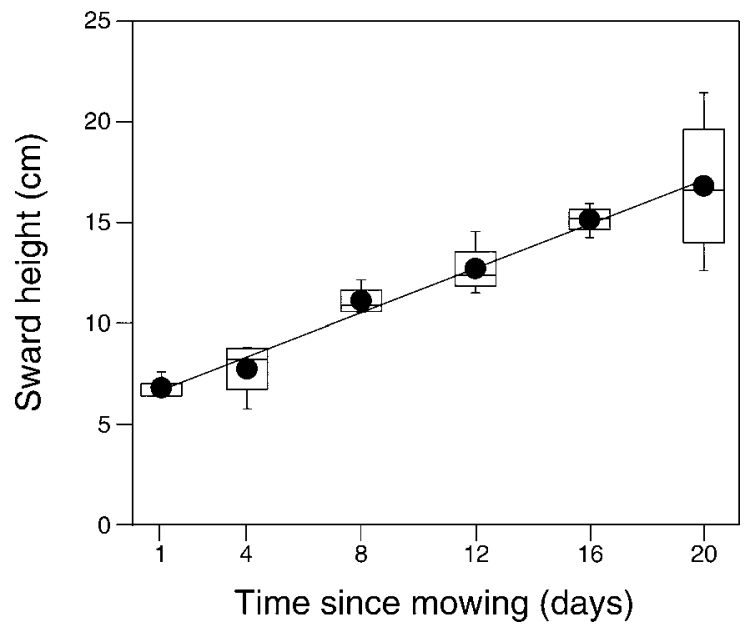

FIG. 2. Sward height increases as a function of experimental treatment (time since mowing; $N=23$ sample plots). These boxand-whisker plots give mean (circle), median (horizontal line within box), interquartile range (box), and range (bars). The line gives the generalized linear model regression.

$$
T_{\mathrm{f}}=\max \left(T_{\mathrm{s}}, T_{\mathrm{h}}\right) .
$$

An increase in bite size $S$ increases handling time linearly, but does not affect searching time. Therefore, a positive (and linear) correlation between $T_{\mathrm{f}}$ and $S$ is diagnostic for process 3 foraging. According to Spalinger and Hobbs, handling time $T_{\mathrm{h}}$ is affected by $S$ in the following manner:

$$
T_{\mathrm{h}}=T_{\mathrm{c}}+T_{\mathrm{p}}=T_{\mathrm{c}}+\frac{S}{R_{\max }}
$$

where $T_{\mathrm{c}}$ is cropping time, $T_{\mathrm{p}}$ is processing (chewing) time, and $R_{\max }$ is the maximum rate of chewing (which would occur in the absence of cropping). Therefore, if process 3 holds, plotting $T_{\mathrm{f}}$ as a function of $S$ yields an estimate of $T_{\mathrm{c}}$ (intercept) and $R_{\max }$ (inverse of the slope).

\section{Material and Methods \\ Experimental design}

In a grassland field at the Centre for Terrestrial Ecology, Netherlands Institute of Ecology, Heteren, The Netherlands, we created a mosaic of 24 plots $(10 \times 10 \mathrm{~m}$ each), in which we manipulated sward height into six categories, leading to a one-factor design with four replicates. Going from short to tall grass, a plot was used $1,4,8,12,16$, or 20 days after it was mowed (Fig. $2)$. The spatial alignment of this mowing scheme followed a randomized block design, with four blocks of each six plots. Each plot was only used for a single trial, leading to 24 trials in total.

Six captive Bewick's Swans were used in this experiment (all adults; three of them were wild-caught [two males, one female]; the other three were born in captivity [one male, two females]). In each trial, the birds were grouped into three pairs (pair 1, containing individuals $\mathrm{AN}$ and $\mathrm{BD}$; pair 2, $\mathrm{AP}$ and $\mathrm{AT}$; pair 3, $\mathrm{BA}$ and $\mathrm{BB}$ ), each pair feeding at a fenced quarter of an experimental plot (leading to four subplots per plot, of which one served as a control subplot). Two pairs adjusted well to the daily protocol and fed normally within the experimental plots (pairs 1 and 3). Although pair 2 occasionally seemed less motivated to participate, we nevertheless maintained it in the analyses (but we will compare the results both with and without this pair). Furthermore, during one trial one of the pairs escaped (pair 3), causing anxiety among the other individuals, which is why this single trial was omitted from the analyses. Therefore, 23 trials remained for the analyses. We performed one trial per day, and each trial was recorded on video (digital video camera NV-GS15; Panasonic, Secaucus, New Jersey, USA).

As a check on our experimental treatments, we sampled sward height in the control subplot immediately after a trial had ended. We did so by measuring the length of individual plants to the nearest $0.5 \mathrm{~cm}$ at 10 randomly selected spots within the subplot. These measurements revealed that the manipulation of sward height worked out as originally planned (Fig. 2). As it turned out, the grass was apparently mowed down to a height of $6.1 \pm 0.7 \mathrm{~cm}$ (intercept; mean $\pm \mathrm{SE}$ ) and grew about $0.5 \pm 0.1 \mathrm{~cm} / \mathrm{d}$ (slope). Henceforth, treatments differed by at least $1.6 \mathrm{~cm}$ from one another $(P<$ $0.00001, N=23$; using the GLM-package in SYSTAT 10 [SYSTAT Software 2000]).

\section{Experimental procedures}

We performed trials from 07:30 to 11:00 hours four days per week (Tuesday-Friday). In order to keep the birds motivated to eat during the trials, they were given no additional food on trial days and on Mondays. Drinking water was always available. Only during weekends were they given extra food (a mixture of commercial food pellets [Natural Free Range Layer Pellets; HAVENS Graanhandel NV, Maashees, The Netherlands] and seed-based mixed grains [Van Havens Green-Line and Natural Scratching Grains; HAVENS Graanhandel NV]) in order to regain body mass lost during working days (birds were weighed daily). In order to prevent "post-weekend effects" in their feeding motivation, we never performed trials on Mondays, even though they were housed in the experimental arena on such days. During the weekend, the birds were kept pairwise in large aviaries $(5 \times 10 \times 3 \mathrm{~m})$ next to the experimental grass field.

The estimation of bite size required knowledge of the total fecal dry mass (DM) produced (see Bite size, bite rate, and intake rate for more details on that calculation). Therefore, we collected all droppings after each trial for each pair. This was done in two ways. (1) Directly after a trial, all droppings produced during a trial were collected from each subplot. (2) Since food retention is long in these large birds (up to $8 \mathrm{~h}$; J. A. van 
Gils and A. Gyimesi, unpublished data), the birds were kept pairwise without food for $10 \mathrm{~h}$ in small chambers $(1.5 \times 1 \times 1 \mathrm{~m})$, where droppings would fall through a wide mesh, allowing us to collect all droppings produced after each trial (but originating from the food intake during the trial). In spite of contending with such long retention times, we were sure all droppings originated from food intake during the 3.5 -h trials only as the birds were given no other food on trial days.

\section{Video analyses}

In order to estimate interbite interval $T_{\mathrm{f}}$, we timed each bite of each bird by replaying the videotapes using The Observer (Noldus Information Technology 1997). As we were interested in short-term intake rates during foraging bouts only, we discarded intervals between two successive bites that were due to non-feeding activities such as resting, preening, drinking, vigilance, or having social interactions. Because of the amount of video material to analyze (23 trials with six birds each trial, leading to $483 \mathrm{~h}$ of observations), we only analyzed one quarter of each trial. In order to spread this selection across the entire trial, we analyzed each first minute in a block of four minutes. On average, we obtained estimates for $1381 \pm 89$ (mean $\pm \mathrm{SE}$ ) suitable interbite intervals per pair per trial.

\section{Field observations}

During three winters (2003-2004, 2004-2005, and 2005-2006), from mid-November to mid-March, we observed foraging behavior of free-living Bewick's Swans in grasslands just north of Amersfoort, The Netherlands (Polder Arkemheen and Polder Zeldert; $52^{\circ} 14^{\prime} \mathrm{N}$ and $5^{\circ} 25^{\prime} \mathrm{E}$ ). Observations were made from a car at a distance of 40-300 m using a 20-60× spotting scope (Kowa, Chuo-Ku Tokyo, Japan) and a $60 \times$ optolite (Meade Instruments, Irvine, California, USA). By means of focal sampling during a full hour (Martin and Bateson 1993), one observer counted each bite taken by a haphazardly selected individual (first two winters) or by a known individual carrying a neck collar (third winter; see van Gils et al. 2007 for more details). In order to estimate short-term bite rate, $1 / T_{\mathrm{f}}$, during foraging only, we needed to correct the total bite counts for non-feeding bouts. Therefore, we additionally scored the focal bird's behavior (i.e., foraging or not foraging) at the beginning of each minute. Short-term bite rate could then be calculated as the number of bites taken during the full hour divided by the proportion of time spent actively feeding. During the very same hour, another observer kept track of the number of fecal droppings produced. As it turned out to be hard to keep track of the same individual during a full hour (except during the third winter and during all bite scans), we applied the "hourly block method" (Bédard and Gauthier 1986) during the first two winters. This involves observing a single, haphazardly selected individual until losing contact, after which the observer immediately switches to another haphazardly selected individual. This goes on until a full hour has passed. At the end of the day we collected dropping and grass samples at the site of observation in order to assess bite size and sward height. Each day we collected $\sim 15$ droppings $(14.3 \pm 0.4$ [mean $\pm \mathrm{SE}$ ] droppings) and $\sim 0.2 \mathrm{~kg}$ fresh mass of grass (taking intact aboveground leaves only). In the laboratory, length of individual plants was measured to the nearest millimeter in order to assess a sample's sward height (measuring $356 \pm 114$ [mean $\pm \mathrm{SE}$ ] leaves per sample). We observed $4.1 \pm 0.4$ $\mathrm{h} / \mathrm{d}$ during 30 different days, spread evenly across all three field seasons ( $\mathrm{SE}=1.7$ days/winter).

\section{Bite size, bite rate, and intake rate}

Bite size, $S$ (in grams), was calculated as $U / B$, where $U$ is the total amount of ingested grass dry mass (in grams) and $B$ is the total number of bites taken. Both $U$ and $B$ were calculated per pair per trial (experiment) or per individual per hour (field). $U$ was calculated as $F(100 /[100-E])$, where $F$ is the total amount of fecal dry matter and $E$ is the (apparent) digestive efficiency (as a percentage). The total amount of fecal dry matter was either measured directly per pair per trial (experiment) or calculated per capita per hour (field) as the hourly defecation rate times the daily mean fecal dry mass per dropping. The digestive efficiency was calculated as (1$\left.\left[\mathrm{ADF}_{\mathrm{g}} / \mathrm{ADF}_{\mathrm{f}}\right]\right) 100 \%$, where $\mathrm{ADF}_{\mathrm{g}}$ is the concentration (as a percentage) of acid detergent fiber (ADF; cellulose and lignin) in the grass and $\mathrm{ADF}_{\mathrm{f}}$ is the ADF concentration (as a percentage) in the feces. Generally, ADF cannot be digested by herbivorous waterfowl (van Soest 1982, Prop and Vulink 1992) and is therefore often used as a marker (Durant 2003). We measured ADF in a subset of samples using the $\mathrm{ANKOM}^{220}$ Fiber Analyzer (ANKOM Technology, Macedon, New York, USA). In addition, we used near infrared spectroscopy (NIRS; multipurpose analyzer, Bruker Optics, Ettlingen, Germany) to predict ADF concentrations in the remaining samples (i.e., most samples collected in the experiment, all samples collected in the 2003-2004 winter and about half of the samples from the 2005-2006 winter; calibration for grass, $R^{2}=99.6 \%$, root mean square error of estimation [RMSEE] $=0.4$; feces, $R^{2}=99.1 \%$, RMSEE $=0.4$; cross-validation for grass, $R^{2}=74.9 \%$, root mean square error of cross-validation [RMSECV] $=$ 1.7; feces, $R^{2}=87.6$, RMSECV $=0.8$; calibrations and cross-validations were based on the subset of samples just described; see Agnew et al. [2004] for an application of NIRS to predict ADF concentrations in grass). Estimating bite size from fecal dry mass and bite counts is an established method in waterfowl ecology (Owen et al. 1992, Durant et al. 2003). It works well when all droppings originating from the bites observed can be collected (such as in the experiment) or when bite and dropping rate are more or less constant throughout the day (such as in the field $2-3 \mathrm{~h}$ after the initiation of feeding [J. A. van Gils and P. P. de Vries, unpublished 


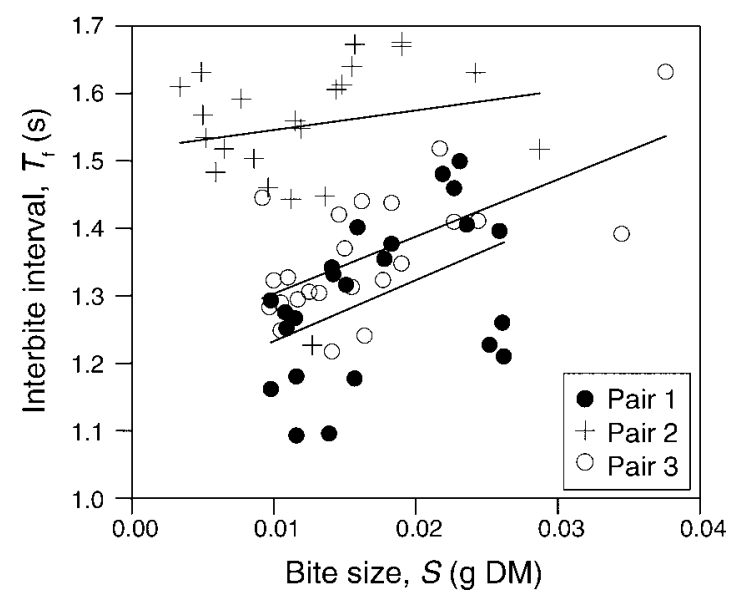

FIG. 3. Interbite interval, $T_{\mathrm{f}}$, increases with bite size, $S$ (DM, dry mass). Each data point gives an estimate per pair per trial, and each line gives a pair-specific regression. For each pair a positive correlation is found, which is support for the Spalinger and Hobbs (1992) process 3 model. Henceforth, the intervals can be interpreted as handling times $\left(T_{\mathrm{h}}\right)$, composed of a cropping time and a bite-size-dependent processing time.

data], which is why nearly all field observations started after 11:00 hours).

In short vegetation, bite size is presumably limited by height of the vegetation, while in taller vegetation bill size may set the limits (Durant et al. 2003, Cope et al. 2005). Therefore, when modeling bite size, $S$, as a function of sward height, $L$, we applied two regression models (using the linear and nonlinear mixed-effects models [NLME] package in $\mathrm{R}$ [R Development Core Team 2005]), one in which we ignored the constraints by bill size,

$$
S=a L+b
$$

and one in which we included an asymptote (cf. Durant et al. 2003),

$$
S=\frac{a L}{1+b L} .
$$

In both models, $a$ and $b$ are regression coefficients. We compared Akaike Information Criterion (AIC) values (Burnham and Anderson 1998) to detect the most parsimonious model (using the ANOVA function in R).

Following Kohlmann et al. (1999), gamma distributions were fitted to the experimentally obtained distributions of intervals $T_{\mathrm{f}}$ (in seconds) between subsequent bites. We applied Kohlmann et al.'s model 1 using the NLME package in R (step sizes in the distributions were set at $0.1 \mathrm{~s}$ ). This yielded an estimated $T_{\mathrm{f}}$ per pair per trial. This enabled the expression of the short-term bite rate (per second) as $1 / T_{\mathrm{f}}$ and the instantaneous intake rate (in grams per second) as $S / T_{\mathrm{f}}$ (note that this contrasts with the calculation of long-term bite rate, which would simply be the total number of bites divided by total time [including non-feeding bouts]).

\section{RESUlts}

\section{Distinguishing encounter-limited foraging from handling-limited foraging}

In the experiment, interbite interval, $T_{\mathrm{f}}$, increased linearly with bite size, $S$ (Fig. 3 ; hierarchical linear model [HLM]: $P<0.05, N=3$ level 2 observations and 69 level 1 observations using the unit of a pair as the identifier; reduced major axis [RMA] regression of $T_{\mathrm{f}}$ [in seconds] vs. $S$ [in grams] yielded $T_{\mathrm{f}}=1.13+16.66 S$; this positive effect remains with a similar slope and intercept, but at $P$ $<0.00001$, with reanalysis excluding the less-motivated pair [2]: $T_{\mathrm{f}}=1.05+16.57 S$ ). Therefore, this result rejects processes 1 and 2 as potential candidate functional responses and supports the process 3 mechanism. Additionally, there was no sign for a mixture of processes operating at the same time. If the smallest bites would be so small that they would impose an encounter constraint rather than a handling constraint, then the relation plotted in Fig. 3 would be accelerating rather than linear (given Eq. 1), and this is obviously not the case. For this reason, interbite interval, $T_{\mathrm{f}}$, can be interpreted as handling time, $T_{\mathrm{h}}$, composed of a fixed cropping time, $T_{\mathrm{c}}$, of $1.13 \mathrm{~s}(=0.02 \mathrm{~min})$ and a bite-size-dependent processing time, $T_{\mathrm{p}}$, of $16.66 \mathrm{~s} / \mathrm{g} \mathrm{DM}$ (Fig. 3; equivalent to an $R_{\max }$ of $3.60 \mathrm{~g} \mathrm{DM} / \mathrm{min}$ ).

\section{Modeling bite size, handling time, and intake rate as a function of sward height}

We modeled bite size as a function of sward height. This enabled us to predict handling time and thus intake rate from relatively simple measurements of sward height rather than from more difficult measurements of bite size.

When relating bite size to the experimentally manipulated sward height, regression parameter $b$ did not differ from 0 in either the linear model (Eq. $3 ; P>0.95$, AIC $=-436.01)$ or the asymptotic model (Eq. $4 ; P>0.6$, AIC $=-435.89)$. Therefore, a linear model without an intercept is the most parsimonious and therefore most preferred model (Fig. 4A; AIC $=-441.89$ ). This allowed us to estimate the common slope (mean $\pm \mathrm{SE}): 1.38 \pm$ $0.09 \mathrm{mg} \mathrm{DM} / \mathrm{cm}$ sward height (Fig. 4A; $P<0.00001, N$ $=3$ level 2 observations and 69 level 1 observations; this result remains unaltered, at a similar $P$ value, if we exclude pair 2: $1.39 \pm 0.07 \mathrm{mg} \mathrm{DM} / \mathrm{cm}$ ).

Combining the latter parameter estimate with the observed relation between handling time, $T_{\mathrm{h}}$ (in minutes), and bite size, $S$ (in grams) $\left(T_{\mathrm{h}}=0.02+\right.$ [S/3.60]; Fig. 3) enabled us to predict $S$ (in grams) $(S=$ $1.38 \times 10^{-3} L$; solid line in Fig. $4 \mathrm{~B}$ ), $T_{\mathrm{h}}$ (in minutes; $T_{\mathrm{h}}=$ $0.02+\left\{\left[1.38 \times 10^{-3} L\right] / 3.60\right\} ;$ Fig. $\left.4 \mathrm{C}\right)$, and subsequently instantaneous intake rate $I=S / T_{\mathrm{h}}$ (in grams per minute) $\left(I=\left[3.60 \times 1.38 \times 10^{-3} L\right] /\left[3.60 \times 0.02+1.38 \times 10^{-3} L\right]\right.$; Fig. 4D) as a function of sward height, $L$ (in centimeters). While doing so, we took into account the error around each estimate (dashed lines in Fig. 4). Note that, as expected under process 3 foraging, the observed 
linear relationship between bite size and sward height leads to an asymptotic relationship between intake rate, $I$, and sward height.

\section{Applying functional response predictions to the field}

Observed sward heights in grasslands selected by freeranging swans ranged from 6 to $12 \mathrm{~cm}(N=30$; Fig. 4B$\mathrm{D}$; the longest grass lengths used in the experiment [15$20 \mathrm{~cm}$ ] were simply not available in the field at this time of year; J. A. van Gils and P. P. de Vries, unpublished data). This range was used as input to predict functional response parameters in the field (Fig. 4B-D). This revealed that estimates for bite size (Fig. 4B), handling time (Fig. 4C), and intake rate $I=S / T_{\mathrm{h}}$ (Fig. 4D) match well with these predictions as each estimate fell within the predicted $95 \% \mathrm{CI}$.

\section{Discussion}

In the experiment, the time in between two bites increased with bite size (Fig. 3), which is indicative of handling-limited foraging, i.e., Spalinger and Hobbs' (1992) process 3. Thus, instantaneous intake rate in grass-eating Bewick's Swans is constrained by rates of cropping and chewing rather than by rates of encounter, leading to an asymptotic Type II functional response with the asymptote being given by $R_{\max }$. The experimentally observed quantitative dependence of bite size on sward height (Fig. 4A) was used to predict bite sizes (Fig. 4B) and subsequently handling times (Fig. 4C) and intake rates (Fig. 4D) as a function of sward height in the field. Observed bite sizes, handling times, and intake rates in the field closely matched these experiment-based predictions (Fig. 4B-D).

The fact that intake rate in grass-eating Bewick's Swans was constrained by bite mass (process 3 ) rather than by plant density (processes 1 and 2) may not come as a surprise. Individual grass stems (1) are not hidden and (2) are interspaced at very short distances, such that the time to move from one bite to the next bite is virtually negligible. Indeed, when applying the concept introduced by Hobbs et al. (2003), who explicitly addressed the problem of plant density on intake rate regulation, we arrive at estimated critical distances $d^{*}$ between individual bites ranging from $14 \mathrm{~cm}$ (for the shortest sward heights of $6 \mathrm{~cm}$ ) to $38 \mathrm{~cm}$ (for the longest sward heights of $17 \mathrm{~cm}$ ), above which intake rate in grass-eating swans would be encounter-limited instead of handling-limited. (Following Hobbs et al. [2003], we calculated $d^{*}$ as $\mathrm{SV}_{\max } / R_{\max }$, using the allometric mammalian equation for $V_{\max }$ [Shipley et al. 1996], i.e., the velocity of travel in the absence of cropping at a body mass of $5.5 \mathrm{~kg}$ and assuming the number of leaves per bite does not vary with plant density, which is in line with observations by Lang and Black [2001]). Grass ramets are interspersed at much shorter distances than $14 \mathrm{~cm}$ (J. A. van Gils and P. P. de Vries, personal observation), and therefore handling-limited foraging was to be expected.
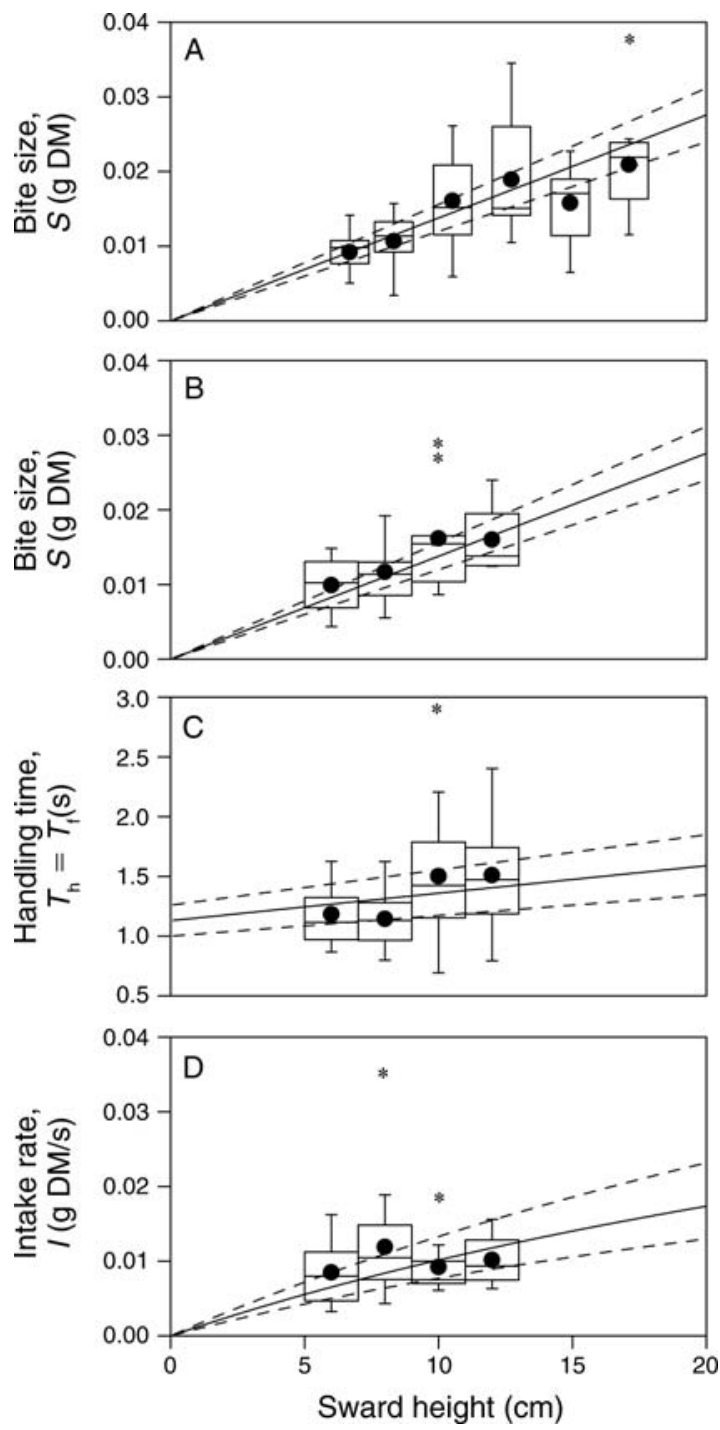

FIG. 4. (A) Experimental results on bite size, $S$ (DM, dry mass), as a function of sward height. The solid line gives the hierarchical linear model regression; dashed lines give the $95 \%$ CI. Field results on (B) bite size, $S$, (C) handling time, $T_{\mathrm{h}}(=$ interbite interval, $T_{\mathrm{f}}$ ), and (D) intake rate, $I$, match with experiment-based predictions (solid line, regression; dashed lines give the 95\% CI). Box-and-whisker plots are as in Fig. 2, with asterisks denoting outliers.

However, Durant et al. (2003) suggested that grass eating in the smaller avian herbivores in their study (the Eurasian Wigeon [Anas penelope] and Barnacle Geese [Branta leucopsis]) shifted from handling-limited toward encounter-limited as sward heights increased. They suggested that at tall sward heights small birds need more time locating suitable bites (in addition to more time needed for cropping as found in that study). This may lead to the so-called "dome-shaped" functional response (or Holling's [1965] Type IV functional response), in which intake rate peaks at intermediate biomass (van der Wal et al. 1998, Therkildsen and 

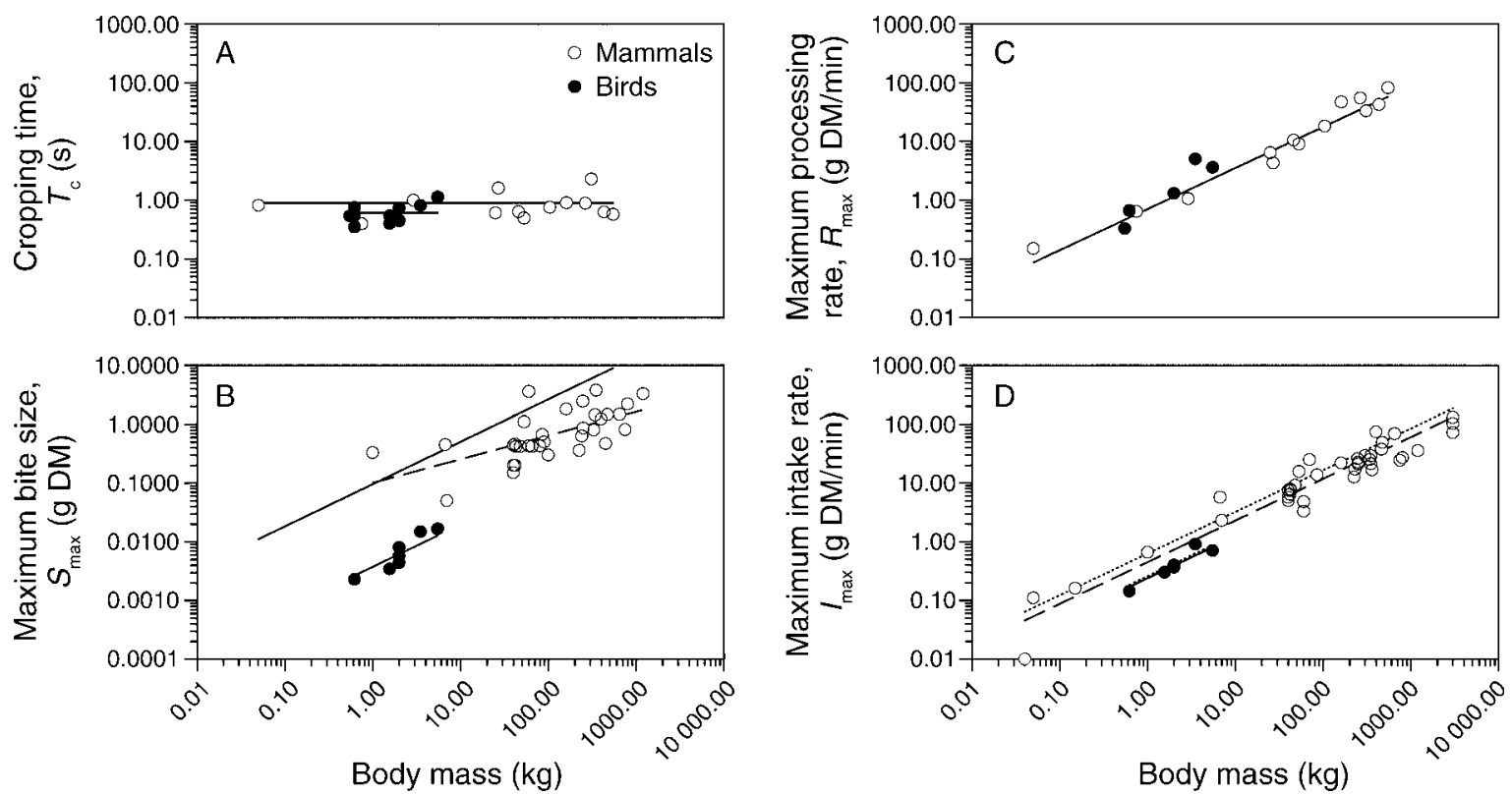

FIG. 5. Allometric scaling (note the log scales) of functional response parameters in birds (solid circles) in comparison with mammals (open circles). (A) Cropping time, $T_{\mathrm{c}}$, does not relate to body mass and is slightly lower than in mammals. (B) Maximum bite size, $S_{\max }$ (DM, dry mass), scales to body mass with a similar slope but a lower intercept than in mammals. (C) Maximum food processing rate, $R_{\max }$, scales to body mass with a similar slope and intercept as in mammals. (D) Maximum intake rate, $I_{\max }$, scales to body mass with a similar slope but with an intercept half that in mammals. In each graph (A-D), solid lines give regressions for mammals and birds; dashed lines (B and D) give regressions through additional mammalian data reviewed by Shipley et al. (1994); dotted lines (D) give predicted $I_{\max }$ on the basis of scaling relations for $T_{\mathrm{c}}, S_{\max }$, and $R_{\max }$. All mammalian data were taken from Shipley et al. (1994); avian data were taken from Jacobsen (1992), Hewitt and Kirkpatrick (1996), Hassall et al. (2001), Lang and Black (2001), Durant et al. (2003), Cope et al. (2005), Durant and Fritz (2005), and van der Graaf et al. (2005) (see Appendix A for details).

Madsen 2000, Lang and Black 2001, Bos et al. 2004). Smaller grazers may need to be more selective as the morphology of their bills seems to be a compromise between conflicting functional demands of grazing on the one hand and filter-feeding on the other (van der Leeuw et al. 2003). Larger avian herbivores, such as the Greylag Goose (Anser anser) and the Bewick's Swan (this study), do not seem to have such problems and therefore obey the process 3 equation across all sward heights studied.

To quantify such effects of avian body size on functional response parameters, we allometrically scaled the results of our study to parameters found in other avian herbivores and contrasted those with parameters found in mammals (Shipley et al. 1994). The avian herbivores that we included were (in increasing order of size): Ruffed Grouse (Bonasa umbellus; Hewitt and Kirkpatrick 1996), Eurasian Wigeon (Anas penelope; Jacobsen 1992, Durant et al. 2003, Durant and Fritz 2005), Brent Goose (Branta bernicla; Hassall et al. 2001), Barnacle Goose (Branta leucopsis; Lang and Black 2001, Durant et al. 2003, Cope et al. 2005, van der Graaf et al. 2005), and Greylag Goose (Anser anser; Durant et al. 2003) (see Appendix A for details).

As in mammals, cropping times, $T_{\mathrm{c}}$, in birds did not scale to body mass $(P>0.1)$. The intercept however, was slightly but significantly $(P<0.005)$ lower in birds
$(0.6 \mathrm{~s})$ than in mammals $(0.9 \mathrm{~s})$. The fact that, also in birds, cropping time does not scale to body mass suggests that plant characteristics such as leaf stiffness overrule the potential effects of body size on cropping time. Maximum bite size, $S_{\max }$ (in grams DM), scaled to body mass, $M$ (in kilograms; Fig. 5B; $P<0.005$ ), with a similar slope as in mammals $(P>0.15)$, but with a lower intercept $\left(P<0.00001\right.$; mammals, $S_{\max }=0.09 M^{0.72}$, using the experimentally obtained equation by Shipley et al. [1994]; solid line in our Fig. 5B; birds, $S_{\max }=$ $0.004 M^{0.72}$ ). Mammals are likely to take larger bites because their teeth may enable more plant material to be cut in a single bite, even so that a bite may extend outside their mouths (Shipley et al. 1994). Note that large avian herbivores such as geese and swans have evolved tooth-like lamellae in their bills, and it is suggested that this improved their bite size (van der Leeuw et al. 2003). The possibility of mammals having larger "beaks" enabling larger bites is precluded as beak dimensions do not differ between birds and mammals (bill widths exactly overlap with the mammalian allometric regression for incisor breadth provided by Illius and Gordon [1987], and similarly, bill lengths scale identically to body mass in birds as do jaw lengths in mammals [based on data provided by Druzinsky 1993]). Maximum processing rate, $R_{\max }$ (in grams DM per minute), scaled to body mass (in kilograms; Fig. 5C; $P<$ 


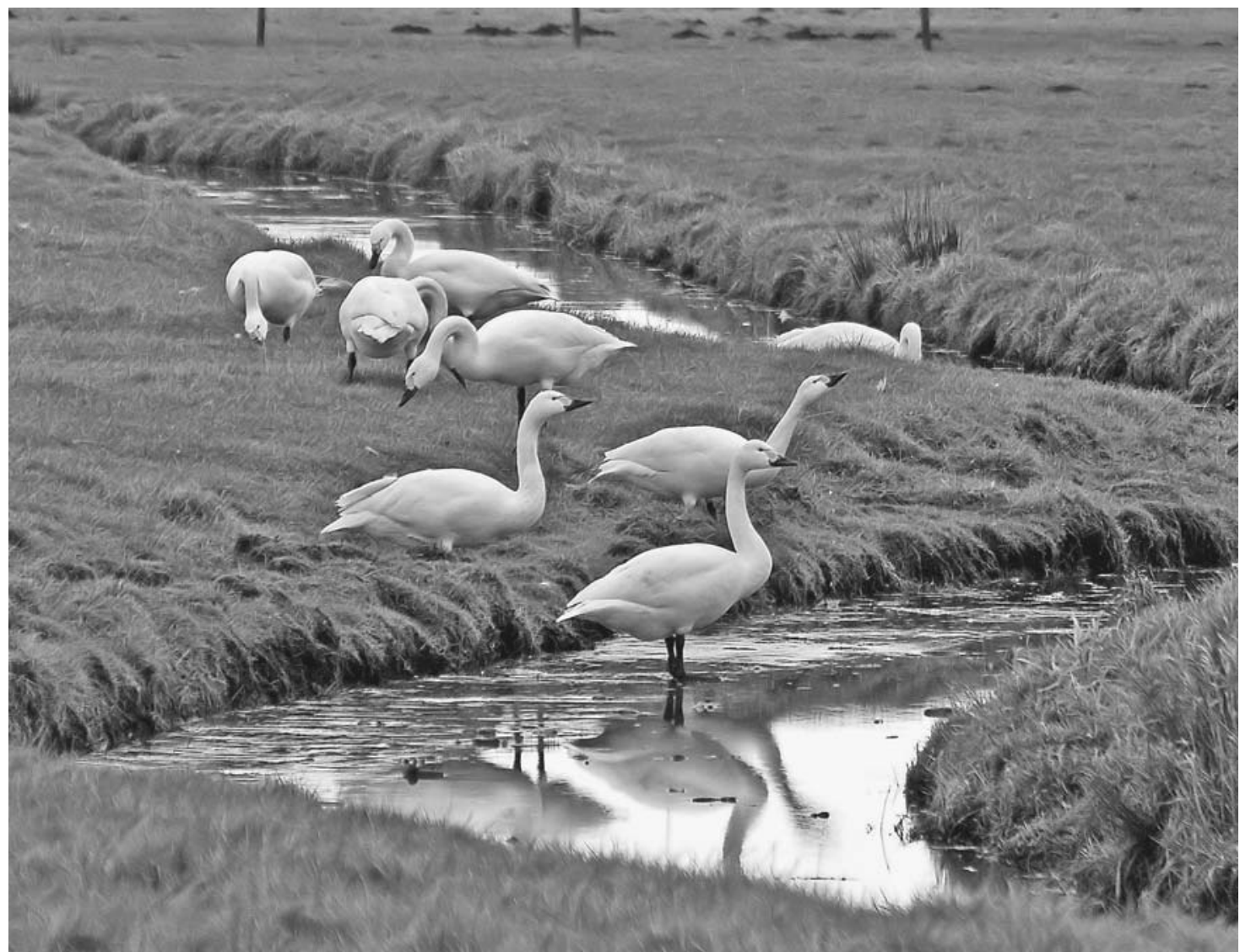

Plate 1. A typical flock of free-ranging Bewick's Swans feeding in our field site near Amersfoort, The Netherlands. Photo credit: Alex Koenders.

$0.05)$ with a similar slope $(P>0.2)$ and intercept $(P>$ $0.2)$ as in mammals $\left(R_{\max }=0.71 M^{0.70}\right)$. This may seem remarkable at first, since birds, unlike mammals, do not chew and would therefore be expected to have higher maximum processing rates. However, because they do not chew, it may take them longer to maneuver tall grass leaves that are hanging out of the bill into the mouth (Fig. 1). This so-called "spaghetti effect" (Ungar 1996) has been observed in a variety of waterfowl species (Lang and Black 2001, Durant et al. 2003). The time loss of the "spaghetti effect" in birds may be similar to the time loss of chewing in mammals, which would explain the similarity in maximum processing rate. Maximum intake rate, $I_{\max }$ (in grams DM per minute), scaled to body mass (in kilograms; Fig. 5D; $P<0.005$ ) with a similar slope as in mammals $(P>0.4)$, but with an intercept two times lower $\left(P<0.005\right.$; mammals, $I_{\max }=$ $0.45 M^{0.71}$; birds, $\left.I_{\max }=0.24 M^{0.71}\right)$. Note that these maximum intake rates are correctly predicted by inserting the allometric scaling relationship for $T_{\mathrm{c}}, S_{\max }$, and $R_{\max }$ into Eq. 2 (yielding $I_{\max }=0.26 M^{0.71}$ for birds and comparable to $0.63 M^{0.71}$ predicted by Shipley et al. [1994] for mammals; dotted lines in Fig. 5D), which is an additional support for avian herbivory to be governed by Spalinger and Hobbs process 3 (i.e., given that $T_{\mathrm{c}}$ and $R_{\max }$ do not differ much between equally sized birds and mammals, a lower $S_{\max }$ in birds logically leads to a lower $I_{\max }$ under process 3 foraging).

In their struggle to at least maintain a balanced energy budget, there may be several ways in which birds could compensate for such lower (instantaneous) intake rates that are only half those of mammals. First of all, they could be better at digesting their food. However, this seems unlikely as evidence suggests birds have similar or even lower digestive efficiencies than mammals (Karasov 1990, Grajal 1995), possibly because the ability to fly has precluded the evolution of a complex and heavy digestive system as found in mammals (Dudley and Vermeij 1992). Secondly, birds may have lower energy requirements than mammals. Also this seems unlikely as birds generally have similar or even higher metabolic rates than mammals (Nagy 2005). Thirdly, and most likely, birds spend more time feeding per day than mammals do. Indeed, when contrasting herbivorous birds with herbivorous mammals, we found that birds allocated more than twice (2.4 times) as much time to foraging $(9.7 \pm 0.6 \mathrm{~h}$ per $24 \mathrm{~h})($ mean \pm SE) than mammals did $\left(4.1 \pm 0.6 \mathrm{~h}\right.$ per $24 \mathrm{~h} ; R^{2}=0.54, P<$ 
0.00001, $N=42$; see Appendix B for studies reviewed). Note that the factor 2.4 exactly matches the ratio between the mechanistically predicted $I_{\max }$ of a mammal and that of a bird: $0.63 M^{0.71} / 0.26 M^{0.71}=2.4$. Further note that this analysis does not suggest that mammals are not able to feed longer than this. It rather suggests that, generally speaking, they do not need to feed longer in order to maintain a balanced energy budget. Of course, under more stringent conditions, such as when their population has grown to carrying capacity, shortterm intake rates may fall well below $I_{\max }$ (e.g., due to competition), urging mammals to stretch their working day as well (a point of view shared by Jeschke and Tollrian [2005]).

\section{ACKNOWLEDGMENTS}

We are grateful to Pieter Coehoorn, Els Corporaal, Bert Hidding, Rik van Kraaij, Rinze de Leeuw, Daan Liefhebber, Reinder Radersma, and Peter de Vries for their observations during many long, cold, and windy hours in the field. In the lab, Dick Kuiper from the Van Hall Instituut assisted during the ADF analyses, and Harry Korthals took care of all NIRS measurements. We thank Marcel Klaassen for discussion and Olivier Duriez, Stephan G. Kohlmann, Bart A. Nolet, and two anonymous referees for constructive comments on draft manuscripts. The experiment was approved by the Dutch Animal Welfare Committee (protocol CL 03.04). This is publication 4020 of the Netherlands Institute of Ecology (NIOO-KNAW) and 481 of the Centre for Wetland Ecology.

\section{Literature Cited}

Agnew, R. E., R. S. Park, C. S. Mayne, and A. S. Laidlaw. 2004. Potential of near infrared spectroscopy to predict the voluntary intake of grazed grass. Animal Feed Science and Technology 115:169-178.

Augustine, D. J., L. E. Frelich, and P. A. Jordan. 1998. Evidence for two alternate stable states in an ungulate grazing system. Ecological Applications 8:1260-1269.

Bédard, J., and G. Gauthier. 1986. Assessment of faecal output in geese. Journal of Applied Ecology 23:77-90.

Bergman, C. M., J. M. Fryxell, C. C. Gates, and D. Fortin. 2001. Ungulate foraging strategies: Energy maximizing or time minimizing? Journal of Animal Ecology 70:289-300.

Bos, D., J. van de Koppel, and F. J. Weissing. 2004. Darkbellied Brent geese aggregate to cope with increased levels of primary production. Oikos 107:485-496.

Bradbury, J. W., S. L. Vehrencamp, K. E. Clifton, and L. M. Clifton. 1996. The relationship between bite rate and local forage abundance in wild Thomson's gazelles. Ecology 77: 2237-2255.

Burnham, K. P., and D. R. Anderson. 1998. Model selection and inference: a practical information-theoretic approach. Springer-Verlag, New York, New York, USA.

Charman, K. 1979. Feeding ecology and energetics of the darkbellied Brent goose (Branta bernicla bernicla) in Essex and Kent. Pages 451-465 in R. L. Jefferies and A. Davies, editors. Ecological processes in coastal environments. Blackwood, London, UK.

Cope, D. R., M. J. J. E. Loonen, J. M. Rowcliffe, and R. A. Pettifor. 2005. Larger barnacle geese (Branta leucopsis) are more efficient feeders: a possible mechanism for observed body size-fitness relationships. Journal of Zoology 265:3742.

Druzinsky, R. E. 1993. The time allometry of mammalian chewing movements: chewing frequency scales with body mass in mammals. Journal of Theoretical Biology 160:427440.

Dudley, R., and G. J. Vermeij. 1992. Do the power requirements of flapping flight constrain folivory in flying animals? Functional Ecology 6:101-104.

Durant, D. 2003. The digestion of fibre in herbivorous Anatidae - a review. Wildfowl 54:7-24.

Durant, D., and H. Fritz. 2005. Variation of pecking rate with sward height in wild wigeon Anas penelope. Journal of Ornithology 147:367-370.

Durant, D., H. Fritz, S. Blais, and P. Duncan. 2003. The functional response in three species of herbivorous Anatidae: effects of sward height, body mass and bill size. Journal of Animal Ecology 72:220-231.

Ginnett, T. F., and M. W. Demment. 1995. The functional response of herbivores - analysis and test of a simple mechanistic model. Functional Ecology 9:376-384.

Grajal, A. 1995. Digestive efficiency of the hoatzin, Opisthocomus hoazin - a folivorous bird with foregut fermentation. Ibis 137:383-388.

Gross, J. E., L. A. Shipley, N. T. Hobbs, D. E. Spalinger, and B. A. Wunder. 1993. Functional response of herbivores in food-concentrated patches: tests of a mechanistic model. Ecology 74:778-791.

Hassall, M., R. Riddington, and A. Helden. 2001. Foraging behaviour of Brent geese, Branta b. bernicla, on grasslands: effects of sward length and nitrogen content. Oecologia 127: 97-104.

Hewitt, D. G., and R. L. Kirkpatrick. 1996. Forage intake rates of ruffed grouse and potential effects on grouse density. Canadian Journal of Zoology 74:2016-2024.

Hobbs, N. T., J. E. Gross, L. A. Shipley, D. E. Spalinger, and B. A. Wunder. 2003. Herbivore functional response in heterogeneous environments: a contest among models. Ecology 84:666-681.

Holling, C. S. 1959. Some characteristics of simple types of predation and parasitism. Canadian Entomologist 91:385398.

Holling, C. S. 1965. The functional response of predators to prey density and its role in mimicry and population regulation. Memoires of the Entomological Society of Canada 45:3-60.

Holling, C. S. 1966. The functional response of invertebrate predators to prey density. Memoires of the Entomological Society of Canada 48:1-86.

Illius, A. W., P. Duncan, C. Richard, and P. Mesochina. 2002. Mechanisms of functional response and resource exploitation in browsing roe deer. Journal of Animal Ecology 71:723-734.

Illius, A. W., and I. J. Gordon. 1987. The allometry of food intake in grazing ruminants. Journal of Animal Ecology 56: 989-999.

Jacobsen, O. W. 1992. Factors affecting selection of nitrogenfertilized grassland areas by breeding wigeon Anas penelope. Ornis Scandinavica 23:121-131.

Jeschke, J. M., M. Kopp, and R. Tollrian. 2002. Predator functional responses: discriminating between handling and digesting prey. Ecological Monographs 72:95-112.

Jeschke, J. M., and R. Tollrian. 2005. Predicting herbivore feeding times. Ethology 111:187-206.

Karasov, W. H. 1990. Digestion in birds: chemical and physiological determinants and ecological implications. Studies in Avian Biology 13:391-415.

Kohlmann, S. G., J. H. Matis, and K. L. Risenhoover. 1999. Estimating handling times for herbivore diets: a statistical method using the gamma distribution. Journal of Animal Ecology 68:638-645.

Lang, A., and J. M. Black. 2001. Foraging efficiency in Barnacle geese Branta leucopsis: a functional response to 
sward height and an analysis of sources of individual variation. Wildfowl 52:7-20.

Lang, A., A. I. Houston, J. M. Black, R. A. Pettifor, and J. Prop. 1998. From individual feeding performance to predicting population dynamics in barnacle geese: the spring staging model. Norsk Polarinstitutt Skrifter 200:203-211.

Martin, P., and P. Bateson. 1993. Measuring behaviour: an introductory guide. Cambridge University Press, Cambridge, UK.

Nagy, K. A. 2005. Field metabolic rate and body size. Journal of Experimental Biology 208:1621-1625.

Noldus Information Technology. 1997. The Observer: support package for video analysis. Reference manual. Version 4.0 for Windows edition. Noldus Information Technology, Wageningen, The Netherlands.

Nolet, B. A., O. Langevoord, R. M. Bevan, K. R. Engelaar, M. Klaassen, R. J. W. Mulder, and S. van Dijk. 2001. Spatial variation in tuber depletion by swans explained by differences in net intake rates. Ecology 82:1655-1667.

Owen, M., R. L. Wells, and J. M. Black. 1992. Energy budgets of wintering barnacle geese: the effects of declining food resources. Ornis Scandinavica 23:451-458.

Pettifor, R. A., R. W. G. Caldow, J. M. Rowcliffe, J. D. GossCustard, J. M. Black, K. H. Hodder, A. I. Houston, A. Lang, and J. Webb. 2000. Spatially explicit, individual-based, behavioural models of the annual cycle of two migratory goose populations. Journal of Applied Ecology 37:s103-135.

Piersma, T., J. van Gils, P. de Goeij, and J. van der Meer. 1995. Holling's functional response model as a tool to link the food-finding mechanism of a probing shorebird with its spatial distribution. Journal of Animal Ecology 64:493-504.

Prop, J. 1991. Food exploitation patterns by brent geese during spring staging. Ardea 79:331-342.

Prop, J., and T. Vulink. 1992. Digestion by barnacle geese in the annual cycle: the interplay between retention time and food quality. Functional Ecology 6:180-189.

R Development Core Team. 2005. R: A language and environment for statistical computing. R Foundation for Statistical Computing, Vienna, Austria.

Searle, K. R., T. Vandervelde, N. T. Hobbs, and L. A. Shipley. 2005. Gain functions for large herbivores: tests of alternative models. Journal of Animal Ecology 74:181-189.
Shipley, L. A., J. E. Gross, D. E. Spalinger, N. T. Hobbs, and B. A. Wunder. 1994. The scaling of intake rate in mammalian herbivores. American Naturalist 143:1055-1082.

Shipley, L. A., D. E. Spalinger, J. E. Gross, N. T. Hobbs, and B. A. Wunder. 1996. The dynamics and scaling of foraging velocity and encounter rate in mammalian herbivores. Functional Ecology 10:234-244.

Spalinger, D. E., and N. T. Hobbs. 1992. Mechanisms of foraging in mammalian herbivores: new models of functional response. American Naturalist 140:325-348.

SYSTAT Software. 2000. SYSTAT. Version 10. SYSTAT Software, Point Richmond, California, USA.

Therkildsen, O. R., and J. Madsen. 2000. Assessment of food intake rates in pink-footed geese Anser brachyrhynchus based on examination of oesophagus contents. Wildlife Biology 6: 167-172.

Ungar, E. D. 1996. Ingestive behaviour. Pages 185-218 in J. Hodgson and A. W. Illius, editors. The ecology and management of grazing systems. CAB International, Wallingford, UK.

Van der Graaf, A. J., P. Coehoorn, and J. Stahl. 2005. Sward height and bite size affect the functional response of barnacle geese Branta leucopsis. Journal of Ornithology 147:479-484.

Van der Leeuw, A. H. J., K. Kurk, P. C. Snelderwaard, R. G. Bout, and H. Berkhoudt. 2003. Conflicting demands on the trophic system of Anseriformes and their evolutionary implications. Animal Biology 53:259-301.

Vandermeer, J. H., and D. E. Goldberg. 2003. Population ecology: first principles. Princeton University Press, Princeton, New Jersey, USA.

Van der Wal, R., J. van de Koppel, and M. Sagel. 1998. On the relation between herbivore foraging efficiency and plant standing crop: an experiment with barnacle geese. Oikos 82: 123-130.

Van Gils, J. A., V. J. Munster, R. Radersma, D. Liefhebber, R. A. M. Fouchier, and M. Klaassen. 2007. Hampered foraging and migratory performance in swans infected with low-pathogenic avian influenza A virus. PLoS ONE 2(1): e184.

Van Soest, P. J. 1982. Nutritional ecology of the ruminant. O and B Books, Corvallis, Oregon, USA.

\section{APPENDIX A} A1).

The method used for extracting functional response parameters from studies on avian herbivores (Ecological Archives E088-182-

\section{APPENDIX B}

The method used for extracting daily feeding times from studies on avian and mammalian herbivores (Ecological Archives E088182-A2). 